\title{
Kamu Kurum ve Kuruluşları İçin Ortak Strateji Belirlemede Bir Karar Destek Süreci
}

\author{
Feyza Gürbüz ${ }^{1 *}$, Rabia $\mathrm{Ar}^{2}$, Beyza Oğuz ${ }^{3}$ \\ $1^{*}$ Erciyes Üniversitesi, Mühendislik Fakültesi, Endüstri Mühendisliği Bölümü, Kayseri, Türkiye, (ORCID: 0000-0002-6327-8232),feyza@erciyes.edu.tr \\ ${ }^{2}$ Erciyes Üniversitesi, Mühendislik Fakültesi, Endüstri Mühendisliği Bölümü, Kayseri, Türkiye (ORCID: 0000-0002-9497-9090), 1030316003@erciyes.edu.tr \\ ${ }^{3}$ Erciyes Üniversitesi, Mühendislik Fakültesi, Endüstri Mühendisliği Bölümü, Kayseri, Türkiye (ORCID: 0000-0002-7750-743X), 1030315921@erciyes.edu.tr
}

(2nd International Conference on Access to Recent Advances in Engineering and Digitalization (ARACONF)-10-12 March 2021)

(DOI: $10.31590 /$ ejosat.901608)

ATIF/REFERENCE: Gürbüz, F., Arı, R. \& Oğuz, B. (2021). Kamu Kurum ve Kuruluşları İçin Ortak Strateji Belirlemede Bir Karar Destek Süreci. Avrupa Bilim ve Teknoloji Dergisi, (24), 436-444.

\section{$\ddot{O} \mathbf{z}$}

Stratejik planlama, kurumların uzun vadeli stratejilerinin belirlemesi ve kaynaklarını bu stratejiye göre ayarlamasıdır. Stratejik planlamada mevcut durum analizi ile gelecek durum tasarımları yapılmaktadır. Mevcut durum analizinde yapılan çalışmalar, birim görev ve sorumluklarının tespit edilmesi, koordinasyon açısından görevlendirmelerin yapılması, paydaş analizi, iç ve dış çevre analizi, SWOT (S: Güçlü Yönler, W: Zayıf Yönler, O: Fırsatlar, T: Tehditler) analizleridir. SWOT Analizi, kurumların kurumsal işlerliği, rekabet gücü, sektördeki konumu, piyasadaki dış tehditlerin varlığı gibi iç ve dış değerlendirmelerin yapılabildiği yöntemlerdendir. Yapılan çalışmada kamu kurum ve kuruluşlarının güncel stratejik planlarında mevcut bulunan SWOT analizleri metin madenciliği ile analiz edilerek her kurum için ortak kavramlar belirlenerek sonrasında kamu kuruluşlarının gelişimi için ortak stratejilerin hangi konulara odaklanması gerektiğine karar verilecektir.

Anahtar Kelimeler: Stratejik plan, Swot analizi, Metin madenciliği, Ahp.

\section{Decision Support In Setting A Common Strategy For Public Institutions And Organizations}

\begin{abstract}
Strategic planning is for organizations to determine their long-term strategies and to adjust their resources accordingly. In strategic planning, future situation designs are made with the current situation analysis. The studies carried out in the current situation analysis are the determination of unit duties and responsibilities, the realization of assignment limitations in terms of coordination, stakeholder analysis, internal environment analysis, external environment analysis, SWOT analysis. SWOT Analysis is one of the evaluation methods in which internal and external assessments such as corporate functioning of institutions, competitiveness, position in the sector, and presence of external threats in the market can be made. In this study, the SWOT analyses present in the current strategic plans of public institutions and organizations were analyzed with text mining and common concepts were determined for each institution and then joint strategies for the development of public institutions which topics to focus on.
\end{abstract}

Keywords: Strategic plan, Swot analysis, Text mining, Ahp.

* Sorumlu Yazar: feyza@erciyes.edu.tr 


\section{Giriş}

Günümüzde teknoloji hızla yükselip gelişmektedir. Hızla elektronikleşen dünyada internet gündelik yaşamımızın bir parçası haline gelmiştir. Bu büyümeye bağlı olarak dijital verinin toplanması ve saklanmasındaki gelişmeler saklanan verilerin de büyümesine sebep olmuştur. Toplanan veriler de her geçen gün artmaktadır. Yapılan market alışverişlerinden banka kayıtlarına ya da kullanılan telefonlardaki parmak izi ve retina kayıtlarına kadar gündelik yaşantımızda devamlı olarak veri oluşturulmaktadır.

Verilerin doğru bir biçimde analiz edilip anlamlı bir bilgiye dönüşmesi noktasında veri madenciliği devreye girmektedir.

Kamu kurum ve kuruluşları, işletmeler mevcut durumlarını görmek ve gelecek durum tasarımlarını yapmak adına stratejik plan oluştururlar. Stratejik plan içinde mevcut durum analizini daha net özümsenmesi adına SWOT analizi yapılır.

Swot analizini ilk olarak Albert S. Humphrey tarafindan, bilgileri karar verme için net bir şekilde sunan ve düzenleyen karmaşık stratejik durumlarla ilgilenen bir araç olarak tanımlamıştır (Büyüközkan vd, 2020).

SWOT analizlerini güçlü yapan açığa çıkmamış firsatları göstererer bunlardan yararlanılmasını sağlamasıdır. Kurumun güçlü yanlarını daha da güçlü hale getirebilmek mümkündür. Aynı zamanda zayıf yönleri görerek tehditlerin kontrol edilmesini ve ortadan kaldırılmasını sağlar. Bunların yanında kuruluş, SWOT çerçevesinde incelenebilir ve işletmeyi rakiplerden ayıracak şekilde stratejiler geliştirilebilmesine olanak sağlar (Büyüközkan vd, 2020).

$\mathrm{Bu}$ çalışmada stratejik planlarını güncel olarak paylaşmış olan ülkemizdeki kamu kurum ve kuruluşlarının swot analizleri toplanarak metin madenciliği ile analiz edilmiştir. Daha sonra hangi kriterlerin seçilmesi gerektiği AHP yöntemine göre belirlenip bunlara göre yeni strateji önerileri yapılmıştır.

Literatürde stratejik plan ve swot analizleri ile ilgili yapılmış çalışmaların bir kısmından aşağıdaki paragrafta bahsedilmiştir.

Erol (2019)'daki çalışmada dinamik ve sürekli değişen, sınırların kalkmış olduğu piyasa şartları altında işletmelerin, içinde bulunduğu durum ve çevreyi analiz edip elde ettiği bulgular sonucu gerekli eylemlerin oluşturulmasına odaklanmıştır. Kumar vd. (2020) yaptıkları çalışmada ağırlıklı olarak, yapılandırılmamış verilerin madenciliği sürecinde kullanılan metin sınıflandırma algoritmalarını inceleyerek, kendi güçlü yönleri, zayıf yönleri, firsatları ve tehditleri (SWOT) açısından kullanımlarının eğilimine ilişkin bir analiz gerçekleştirmişlerdir. Rojas vd. (2018) genel bir Stratejik Plan modeli içinde metin madenciliği (TM) algoritmalarını kullanarak KOBI'ler için stratejik planlar tanımlamak amacıyla otomatik bir yöntem sunmuşlardır. Okumuş (2007) çalışmasında kamu kuruluşlarında stratejik planlama çalışmalarında vizyon oluşturulmasını inceleyerek, İstanbul Büyükşsehir Belediyesi iç paydaşları üzerinde, bir araştırma gerçekleştirilmiştir. İstanbul Büyükşehir Belediyesi'nin iç paydaş kitlesini oluşturan farklı görev gruplarına yapılan anketler ile toplanan verileri tanımsal istatistikler yöntemi, ilişki testleri ve farklılık testleri kapsamında değerlendirmiştir. Karaman (2011) Türkiye'de bulunan devlet üniversitelerinin stratejik planlarında belirttikleri güçlü yönleri, zayıf yönleri, firsatları ve tehditlerinin neler olduğunu saptamak üzere çalışmışlardır. Güryeli (2016) çalışmasında, kamu destekli özel sektör Ar-Ge projeleri seçim probleminin değerlendirme ölçütlerini inceleyerek, bu değerlendirme ölçütleri arasındaki ilişkileri tanımlayan bir ă̆ inşa etmiş ve bu ölçütlerin değerlendirme sürecinde ne ölçüde önemli olduklarını tespit etmiştir.

Projede amaçlanan, kamu kurum ve kuruluşlarının güncel stratejik planlarındaki mevcut durum analizini görebilmek adına oluşturulan SWOT analizlerinin metin madenciliği yardımıyla analiz edilerek güçlü yönlerinin daha da güçlenmesinin sağlanması ve zayıf yönlerinin güçlendirilmesi, firsatlardan güçlü ve zayıf yönlerini avantaja çevrilmesi, tehditlerin önlenmesi adına yeni stratejiler belirlemektir.

\section{Materyal ve Metot}

\subsection{Metin Madenciliği}

Metin madenciliği, yeni ve önceden bilinmeyen bilgilerin çeşitli yazılı kaynaklardan otomatik olarak ayıklanması ile keşfedilmesidir. Metin madenciliği ile şirket içerisinde veya internet üzerinde üretilen yapılandırılmamış veri, analitik bir analize kaynak oluşturulacak hale getirilir (Turban vd., 2011). Metin madenciliği aslında veri madenciliğinin yazılı metinler üzerinden yapılmasına verilen addır. Metin madenciliği, biçimlendirilmemiş yazılı metinlerden anlamlı bilgiler çıkarmayı amaçlayan gelişmekte olan bir teknolojidir (He vd., 2013). Metin madenciliği çalışmaları metinleri veri kaynağı olarak kullanan veri madenciliği (data mining) çalışmasıdır. Diğer bir tanımla metin üzerinden yapısallaştırılmış veri elde etmeyi amaçlar. Örneğin metinlerin sınıflandırılması, bölümlenmesi, metinlerden konu çıkarılması, sınıf taneciklerinin üretilmesi, duygusal analiz, metin özetleme, varlık ilişki modellemesi gibi çalışmaları hedefler (Şeker, 2012). Bu çalışmada elde edilen verilerin metin analizlerinde Rapidminer programının 5.3 sürümü kullanılmıştır.

\subsection{RapidMiner}

RapidMiner, eski adiyla YALE (Yet Another Learning Environment), olarak ilk kez 2001 yllında Ralf Klinkenberg, Ingo Mierswa ve Simon Fischer tarafindan Dortmund Teknik Üniversitesi, yapay zeka biriminde geliştirilmiştir. 2006 yılından itibaren, Ingo Mierswa ve Ralf Klinkenberg tarafindan kurulan Rapid-I isimli şirket tarafindan geliştirilmeye başlanmıştır. 2007 yılında, yazılımın adı YALE'den RapidMiner'a çevrilmiştir. 2013 yılında, şirket yeni ismi olan Rapid-I ile RapidMiner ürününü markalaştırmıştır (Norris 2013). Araştırma ve eğitim alanlarında çokça kullanılmakta olan RapidMiner, Client/server mimarisini kullanabilir ve Software as a Service (SaaS) olarak bir bulut yapısı üzerinde çalışabilmektedir (Url-1). RapidMiner bir topluluk yazılımı (community founded software) olarak nitelendirilmektedir (Şeker, 2012).

\subsection{Analitik Hiyerarşi Prosesi (AHP)}

Analitik hiyerarşi süreci (AHP), karmaşık problemleri çözmek ve analiz etmek için kullanılan çok kriterli bir karar verme tekniğidir. Yöneticiler AHP yöntemini, uygun ve anlaşılması kolay olduğu için, çok yararlı bir karar verme tekniği olarak görmektedir. Vaidya ve Kumar 1983 ile 2003 yılları arasında uluslararası dergilerde yayınlanan 150 yayını gözden geçirmişler ve AHP tekniğinin çözme, seçme, değerlendirme ve karar verme için yararlı olduğu sonucuna varmışlardır (AbdelBasset vd., 2018; Vaidya ve Kumar, 2006).

AHP birkaç adımdan oluşur. İlk adım, problemi daha net anlayabilmek için hiyerarşisini oluşturmaktır. AHP'nin 
hiyerarşisi bir hedef (amaç), karar kriterleri, alt kriterler ve son olarak mevcut tüm alternatiflerden oluşur (Abdel-Basset vd., 2018). AHP hiyerarşisi yapılandırıldıktan sonra ikili karşılaştırma matrisi kriterleri ağırlıklandırmak üzere Saaty’in ölçeği kullanılarak karar vericiler tarafından oluşturulur (Saaty, 1988). Son olarak, alternatiflerin nihai ağırlığı belirlenir ve sıralanır. Ahp yöntemine ait ayrıntılı adımlar Palka vd. (2020) çalışmasında bahsedildiği gibidir.

\subsection{Kamu Kurum ve Kurulușlarının Belirlenmesi}

Ülkemizde toplamda 68 adet kamu kurum ve kuruluşu bulunmaktadır. Yaptığımız çalışmada bu kurumlardan stratejik planları güncel olanlar seçilmiştir. Araştırmada Ek 1'de verilen 28 tane kamu kurum ve kuruluşunun planları ele alınmıştır. Bu planlarda yer alan Swot analizleri incelenerek ortak Swot faktörleri metin madenciliği yöntemi ile belirlenmiştir.

\section{Araştırma Sonuçları ve Tartışma}

\subsection{Metin Madenciliği Analizi ve Sonuçlar}

Kamu kuruluşlarına ait Swot faktörlerinin her biri (Güçlü yönler, Zayıf yönler, Fırsatlar ve Tehditler) ayrı ayrı metin madenciliği ile analiz edilerek bütün kamu kuruluşları için ortak olabilecek Swot faktörleri çıkarılmıştır. Metin analizlerinde Rapidminer programının 5.3 sürümü kullanılmıştır.

Rapid miner Data view aracı ile verilerimiz sınıflandırılmıştır. Şekil 1'de Rapidminer data view aracı örnek ekranı gösterilmiştir. Toplamda 352 tane veri kullanılmıştır. Plot view arac1 scatter ile her bir swot kriterlerinden önemli kriterler belirlenmiştir. Şekil 2'de güçlü yönlerin analiz sonuçları örnek olarak verilmiştir.

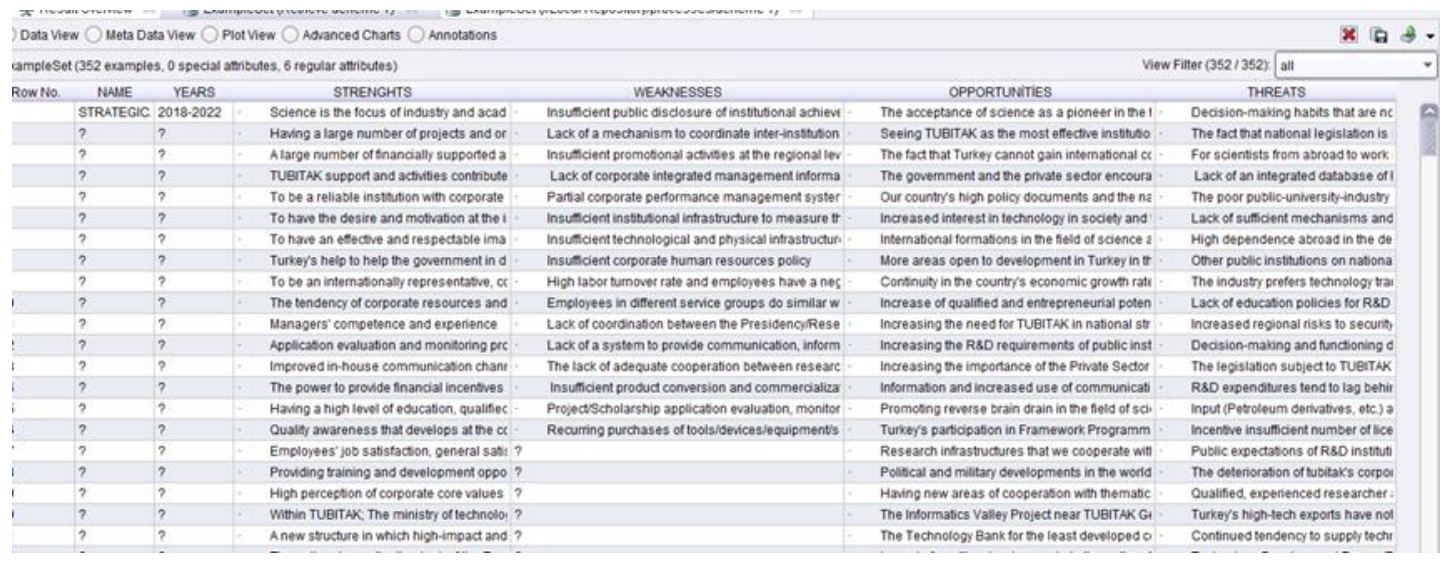

Şekil 1. Rapidminer data view aracı örnek ekranı

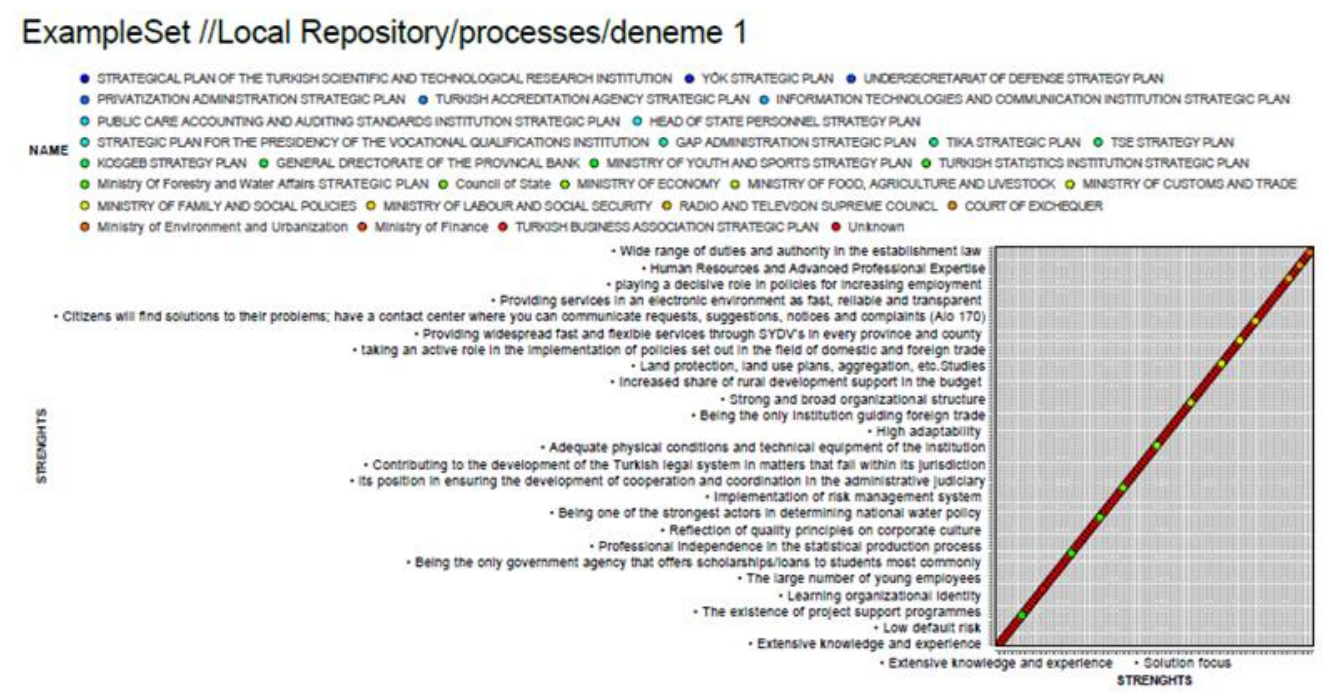

Şekil 2. Plot view aracı ile güçlü yönlerin analizine ait sonuç ekranı

Analiz sonucunda elde edilen 14'er adet Swot alt faktörleri Güçlü yönler, Zayıf yönler, Fırsatlar ve Tehditler için aşağıda sırasıyla verilmiştir.

Güçlü yönler için alt faktörler:
S1: Kentleşmeyi hem politika yapma hem de uygulama fırsatı bulan çok yönlü bir kurum olmak 
S2: Avrupa Birliği Mali Yardım Aracı (IPA) çerçevesinde İnsan Kaynaklarının Geliştirilmesi konusunda program otoritesi olmak

S3: Bütçede kırsal kalkınma desteğinin artan payı

S4: Zengin bir kurum arşivine sahip olmak

S5: Bürokrasi çok fazla değil

S6: Güçlü teknolojik altyapı

S7: Erişilebilir / ulaşılabilir olma

S8: Yurtdışı ofislerin varlığı

S9: Csr No'nun sunduğu olanaklar sayesinde idarenin geniş faaliyet yelpazesi

S10: Uluslararası işbirliğinin etkin kullanımı

S11: Geniş bant internet erişimi ve yaygınlaşacak uygulamalarin

S12: Alanında uzman kadrosunun nitelikli ve tecrübeli insan gücünün varlığ 1

S13: Avrupa Birliği Araştırma ve İnovasyon Çerçeve Programlarının ulusal koordinasyon görevi TÜBİTAK tarafından yürütülmektedir

S14: Bilim, endüstri ve akademik çevrenin ve teknoloji ve yenilik alanındaki devlet kurumlarının odak noktasıdır

Zayıf yönler için alt faktörler: kültür

W1: Mevzuat odaklı yaklaşıma öncelik veren kurumsal

W2: Kurumsal Kültür Zayıflığı

W3: Eğitim politikalarındaki eksiklikler

W4: Taşra teşkilatının hukuki, kurumsal ve insani gelişimi

W5: Biyolojik kaçakçılıkla ilgili sorunlar

W6: Personel eksikliği

W7: Mali kaynaklardaki yetersizlikler

W8: Eğitim olanaklarını homojen kullanmamak

W9: Diğer kurum ve kuruluşlarla yetki çatışması

W10: Teknolojik kapasitenin geliştirilmesi insan kaynağı kapasitesinin geliştirilmesi

W11: Denetçinin uyumu yeterince sağlanmamıştır

W12: "Fizibilite Projelendirme" yaklaşımının olmaması, proje kararlarının alınmasında fizibilitenin etkin kullanımı yeterli

W13: Yüksek Öğretim Kurulunun organizasyon yapısı

W14: Kurumsal başarıların yetersiz kamuya açıklanması

Fırsatlar için alt faktörler:

O1: Teknolojik gelişmeler

O2: Gençlerin teknolojik gelişmelere açıklığ

O3: Uluslararası platformlarda meydana gelen bilimsel ve teknolojik gelişmeleri yakından takip ederek gümrük ve ticaretle ilgili iş ve işlemlerin maliyetini düşürmek, daha hızlı operasyon sağlamak, otomasyonu genişleyerek sınır güvenliğini artırmak
O4: Teknolojik gelişmelerin iş sağlığı ve güvenliğine olumlu etkisi

O5: Yenilenebilir enerjinin yaygın kullanımı katılımı

O6: Nitelikli ve genç insan kaynağının çalışma hayatına

O7: Verimli toprak yapısı ve doğal kaynak çeşitliliği

O8: Marka olabilecek yerel ürünlerin çeşitliliği

O9: Yüksek tarımsal üretim potansiyeli nedeniyle yatırım ve ihracat firsatları

O10: Sürdürülebilir Kalkınma Göstergeleri TüİK koordinatörlüğünde yeni çerçevede üretilecek

O11: Tarihi, sosyal ve kültürel değerlerin zenginliği

O12: Politika dokümanlarında KOBİ, Girişimcilik ve Üretim Sanayinin dönüşümü için alınan önlemlerde artış

O13: Bölge tarihi ve kültürel miras ve doğal kaynaklar açısından zengindir

O14: Kamu Personel Bilgi Sisteminin kurulması tamamland1

Tehditler için alt faktörler:

T1: Bazı alanlarda kurumlar arası yetki ve sorumluluk çatışması

T2: Ekonomik dalgalanmaların işgücü piyasası üzerindeki olumsuz etkisi

T3: Siber tehditlerin bakanlığın teknolojik altyapısına olumsuz etkileri

T4: İklim değişikliği ve çevre kirliliği

T5: Aşırı iş yükü

T6: Geleneksel veri toplama süreçlerinin değişmesiyle büyük veri setlerinin işlenmesi, analizi ve depolanmasındaki zorluklar

T7: Risk altındaki çocukların niceliksel artışı

T8: KOSGEB Destek programlarına benzer programların Diğer Kurum / Kuruluşlar tarafından da sağlanması

T9: Sulama yatırımları bitmiyor

T10: Karar verme sürecini etkileyen bürokratik bir yaklaşım bulmak

T11: İlgili alanda nitelikli insan kaynağı eksikliği

T12: Savunma Sanayi'nin aracı tedarik kurumu olarak algılanması ve fon kaynağı olarak görülmesi

T13: Tübitak'ın kurumsal imajının kamuoyunda bozulması

T14: Genel kamu yönetimi düzeyinde araştırma ve verilere dayanmayan karar alma alışkanlıkları

\subsection{AHP Analizi ve Sonuçlar}

Metin madenciliği sonucu elde edilin Swot faktörlerine ait alt faktörlerin her biri ayrı ayrı AHP yöntemi ile değerlendirilerek sıralanmıştır. AHP analizi için karşılaştırmalar ulaşılabilen ilgili kurum yetkileri uzman çalışanları ile birlikte 
değerlendirilerek ortak kararlarla yapılmıştır. Her bir Swot faktörü için AHP yöntemi adımları sırasıyla uygulanarak ilgili faktörlerin alt faktör sıralamaları elde edilmiştir.

\subsubsection{Güçlï Yönlerin AHP ile Analizi}

Tablo 1. Güçlü yönlere ait karşılaştırma matrisi
Güçlü yönlere ait alt faktörlerin karşılaştırılmalarının yapıldığı matris Tablo 1'de normalize edilmiş karşılaştırma matrisi Tablo 2'de ve sonuç ağırlıklar matrisi ise Tablo 3'de verilmiştir.

\begin{tabular}{|c|c|c|c|c|c|c|c|c|c|c|c|c|c|c|}
\hline & S1 & S2 & S3 & S4 & S5 & S6 & S7 & S8 & S9 & S10 & S11 & S12 & S13 & S14 \\
\hline S1 & 1 & 0,33 & 5 & 1 & 0,33 & 0,2 & 0,33 & 7 & 1 & 0,2 & 0,14 & 0,2 & 5 & 0,33 \\
\hline S2 & 3 & 1 & 5 & 3 & 1 & 0,2 & 3 & 7 & 1 & 0,2 & 0,14 & 0,2 & 5 & 0,33 \\
\hline S3 & $1 / 5$ & 0,2 & 1 & 0,2 & 0,2 & 0,11 & 0,2 & 1 & 0,2 & 0,14 & 0,14 & 0,14 & 1 & 0,14 \\
\hline S4 & 1 & 0,33 & 5 & 1 & 0,33 & 0,14 & 0,33 & 5 & 3 & 0,33 & 0,2 & 0,2 & 3 & 0,2 \\
\hline S5 & 3 & 1 & 5 & 3 & 1 & 0,2 & 3 & 5 & 3 & 0,33 & 0,2 & 0,2 & 5 & 0,2 \\
\hline S6 & 5 & 5 & 9 & 7 & 5 & 1 & 5 & 9 & 7 & 3 & 3 & 3 & 9 & 3 \\
\hline S7 & 3 & 0,33 & 5 & 3 & 0,33 & 0,2 & 1 & 7 & 1 & 0,14 & 0,2 & 0,2 & 3 & 5 \\
\hline S8 & 0,14 & 0,14 & 1 & 0,2 & 0,2 & 0,11 & 0,14 & 1 & 5 & 0,11 & 0,11 & 0,11 & 1 & 0,11 \\
\hline S9 & 1 & 1 & 5 & 0,33 & 0,33 & 0,14 & 1 & 0,2 & 1 & 0,2 & 0,14 & 0,14 & 3 & 0,33 \\
\hline S10 & 5 & 5 & 7 & 3 & 3 & 0,33 & 7 & 9 & 5 & 1 & 0,33 & 0,33 & 7 & 3 \\
\hline S11 & 7 & 7 & 7 & 5 & 5 & 0,33 & 5 & 9 & 7 & 3 & 1 & 3 & 9 & 5 \\
\hline S12 & 5 & 5 & 7 & 5 & 5 & 0,33 & 5 & 9 & 7 & 3 & 0,33 & 1 & 9 & 5 \\
\hline S13 & 0,2 & 0,2 & 1 & 0,33 & 0,2 & 0,11 & 0,33 & 1 & 0,33 & 0,14 & 0,11 & 0,11 & 1 & 0,2 \\
\hline S14 & 3 & 3 & 7 & 5 & 5 & 0,33 & 0,2 & 9 & 3 & 1,33 & 0,2 & 0,2 & 5 & 1 \\
\hline
\end{tabular}

Tablo 2: Normalize edilmiş güçlü yönler matrisi

\begin{tabular}{|c|c|c|c|c|c|c|c|c|c|c|c|c|c|c|}
\hline & S1 & S2 & S3 & S4 & S5 & S6 & S7 & S8 & S9 & S10 & S11 & S12 & S13 & S14 \\
\hline S1 & 0,03 & 0,01 & 0,07 & 0,03 & 0,01 & 0,05 & 0,01 & 0,09 & 0,02 & 0,02 & 0,02 & 0,02 & 0,08 & 0,01 \\
\hline S2 & 0,08 & 0,03 & 0,07 & 0,08 & 0,04 & 0,05 & 0,10 & 0,09 & 0,02 & 0,02 & 0,02 & 0,02 & 0,08 & 0,01 \\
\hline S3 & 0,01 & 0,01 & 0,01 & 0,01 & 0,01 & 0,03 & 0,01 & 0,01 & 0,00 & 0,01 & 0,02 & 0,02 & 0,02 & 0,01 \\
\hline S4 & 0,03 & 0,01 & 0,07 & 0,03 & 0,01 & 0,04 & 0,01 & 0,06 & 0,07 & 0,03 & 0,03 & 0,02 & 0,05 & 0,01 \\
\hline S5 & 0,08 & 0,03 & 0,07 & 0,08 & 0,04 & 0,05 & 0,10 & 0,06 & 0,07 & 0,03 & 0,03 & 0,02 & 0,08 & 0,01 \\
\hline S6 & 0,13 & 0,17 & 0,13 & 0,19 & 0,19 & 0,27 & 0,16 & 0,11 & 0,16 & 0,23 & 0,48 & 0,33 & 0,14 & 0,13 \\
\hline S7 & 0,08 & 0,01 & 0,07 & 0,08 & 0,01 & 0,05 & 0,03 & 0,09 & 0,02 & 0,01 & 0,03 & 0,02 & 0,05 & 0,21 \\
\hline S8 & 0,00 & 0,00 & 0,01 & 0,01 & 0,01 & 0,03 & 0,00 & 0,01 & 0,11 & 0,01 & 0,02 & 0,01 & 0,02 & 0,00 \\
\hline S9 & 0,03 & 0,03 & 0,07 & 0,01 & 0,01 & 0,04 & 0,03 & 0,00 & 0,02 & 0,02 & 0,02 & 0,02 & 0,05 & 0,01 \\
\hline S10 & 0,13 & 0,17 & 0,10 & 0,08 & 0,11 & 0,09 & 0,22 & 0,11 & 0,11 & 0,08 & 0,05 & 0,04 & 0,11 & 0,13 \\
\hline S11 & 0,19 & 0,24 & 0,10 & 0,13 & 0,19 & 0,09 & 0,16 & 0,11 & 0,16 & 0,23 & 0,16 & 0,33 & 0,14 & 0,21 \\
\hline S12 & 0,13 & 0,17 & 0,10 & 0,13 & 0,19 & 0,09 & 0,16 & 0,11 & 0,16 & 0,23 & 0,05 & 0,11 & 0,14 & 0,21 \\
\hline S13 & 0,01 & 0,01 & 0,01 & 0,01 & 0,01 & 0,03 & 0,01 & 0,01 & 0,01 & 0,01 & 0,02 & 0,01 & 0,02 & 0,01 \\
\hline S14 & 0,08 & 0,10 & 0,10 & 0,13 & 0,19 & 0,09 & 0,01 & 0,11 & 0,07 & 0,10 & 0,03 & 0,02 & 0,08 & 0,04 \\
\hline
\end{tabular}

Tablo 3. Güçlü yönlerin ăğrlıkları

\begin{tabular}{|c|c|c|c|c|c|c|c|c|c|c|c|c|c|}
\hline S1 & S2 & S3 & S4 & S5 & S6 & S7 & S8 & S9 & S10 & S11 & S12 & S13 & S14 \\
\hline 0,03 & 0,04 & 0,01 & 0,03 & 0,04 & 0,18 & 0,05 & 0,02 & 0,02 & 0,09 & 0,15 & 0,12 & 0,01 & 0,07 \\
\hline
\end{tabular}

Yapılan AHP analizinden çıkan sonuca göre 'S6' kriteri en iyi sonuç çıkmıştır. Güçlü teknolojik altyapı yani güçlü teknolojik altyapidir.

\subsubsection{Zayıf yönleri AHP ile Analizi}

Zayıf yönlere ait alt faktörlerin karşılaştırılmalarının yapıldığı matris Tablo 4'de normalize edilmiş karşılaştırma matrisi Tablo 5'de ve sonuç ağırlıklar matrisi ise Tablo 6'da verilmiştir. 
European Journal of Science and Technology

Tablo 4. Zayıf yönler karşılaştırma matrisi

\begin{tabular}{|c|c|c|c|c|c|c|c|c|c|c|c|c|c|c|}
\hline & W1 & W2 & W3 & W4 & W5 & W6 & W7 & W8 & W9 & W10 & W11 & W12 & W13 & W14 \\
\hline W1 & 1 & 0,33 & 0,14 & 0,33 & 0,2 & 5 & 0,33 & 0,14 & 0,33 & 0,2 & 1 & 0,2 & 1 & 0,2 \\
\hline W2 & 3 & 1 & 0,2 & 0,33 & 0,33 & 5 & 1 & 0,2 & 0,33 & 0,33 & 0,33 & 0,33 & 1 & 0,2 \\
\hline W3 & 7 & 5 & 1 & 3 & 1 & 7 & 3 & 1 & 3 & 1 & 3 & 1 & 1 & 1 \\
\hline W4 & 3 & 3 & 0,33 & 1 & 1 & 7 & 3 & 1 & 3 & 0,33 & 3 & 1 & 1 & 1 \\
\hline W5 & 5 & 3 & 1 & 1 & 1 & 5 & 3 & 3 & 5 & 3 & 5 & 3 & 1 & 3 \\
\hline W6 & 0,2 & 0,2 & 0,14 & 0,14 & 0,2 & 1 & 0,2 & 0,14 & 0,2 & 0,33 & 0,33 & 0,14 & 1 & 0,2 \\
\hline W7 & 3 & 1 & 0,33 & 0,33 & 0,33 & 5 & 1 & 0,33 & 3 & 0,33 & 3 & 1 & 1 & 1 \\
\hline W8 & 7 & 5 & 1 & 1 & 0,33 & 7 & 3 & 1 & 5 & 1 & 5 & 3 & 1 & 3 \\
\hline W9 & 3 & 3 & 0,33 & 0,33 & 0,2 & 5 & 0,33 & 0,2 & 1 & 0,2 & 1 & 0,33 & 1 & 0,33 \\
\hline W10 & 5 & 3 & 1 & 3 & 0,33 & 3 & 3 & 1 & 5 & 1 & 5 & 5 & 1 & 5 \\
\hline W11 & 1 & 3 & 0,33 & 0,33 & 0,2 & 3 & 0,33 & 0,2 & 1 & 0,2 & 1 & 0,2 & 1 & 0,2 \\
\hline W12 & 5 & 3 & 1 & 1 & 0,33 & 7 & 1 & 0,33 & 3 & 0,2 & 5 & 1 & 1 & 3 \\
\hline W13 & 1 & 1 & 1 & 1 & 1 & 1 & 1 & 1 & 1 & 1 & 1 & 1 & 1 & 1 \\
\hline W14 & 5 & 5 & 1 & 1 & 0,33 & 5 & 1 & 0,33 & 3 & 0,2 & 5 & 0,33 & 1 & 1 \\
\hline
\end{tabular}

Tablo 5. Normalize edilmiş zaylf yönler matrisi

\begin{tabular}{|c|c|c|c|c|c|c|c|c|c|c|c|c|c|c|}
\hline & W1 & W2 & W3 & W4 & W5 & W6 & W7 & W8 & W9 & W10 & W11 & W12 & W13 & W14 \\
\hline W1 & 0,02 & 0,01 & 0,02 & 0,02 & 0,03 & 0,08 & 0,02 & 0,01 & 0,01 & 0,02 & 0,03 & 0,01 & 0,07 & 0,01 \\
\hline W2 & 0,06 & 0,03 & 0,02 & 0,02 & 0,05 & 0,08 & 0,05 & 0,02 & 0,01 & 0,04 & 0,01 & 0,02 & 0,07 & 0,01 \\
\hline W3 & 0,14 & 0,14 & 0,11 & 0,22 & 0,15 & 0,11 & 0,14 & 0,10 & 0,09 & 0,11 & 0,08 & 0,06 & 0,07 & 0,05 \\
\hline W4 & 0,06 & 0,08 & 0,04 & 0,07 & 0,15 & 0,11 & 0,14 & 0,10 & 0,09 & 0,04 & 0,08 & 0,06 & 0,07 & 0,05 \\
\hline W5 & 0,10 & 0,08 & 0,11 & 0,07 & 0,15 & 0,08 & 0,14 & 0,30 & 0,15 & 0,32 & 0,13 & 0,17 & 0,07 & 0,15 \\
\hline W6 & 0,00 & 0,01 & 0,02 & 0,01 & 0,03 & 0,02 & 0,01 & 0,01 & 0,01 & 0,04 & 0,01 & 0,01 & 0,07 & 0,01 \\
\hline W7 & 0,06 & 0,03 & 0,04 & 0,02 & 0,05 & 0,08 & 0,05 & 0,03 & 0,09 & 0,04 & 0,08 & 0,06 & 0,07 & 0,05 \\
\hline W8 & 0,14 & 0,14 & 0,11 & 0,07 & 0,05 & 0,11 & 0,14 & 0,10 & 0,15 & 0,11 & 0,13 & 0,17 & 0,07 & 0,15 \\
\hline W9 & 0,06 & 0,08 & 0,04 & 0,02 & 0,03 & 0,08 & 0,02 & 0,02 & 0,03 & 0,02 & 0,03 & 0,02 & 0,07 & 0,02 \\
\hline W10 & 0,10 & 0,08 & 0,11 & 0,22 & 0,05 & 0,05 & 0,14 & 0,10 & 0,15 & 0,11 & 0,13 & 0,29 & 0,07 & 0,25 \\
\hline W11 & 0,02 & 0,08 & 0,04 & 0,02 & 0,03 & 0,05 & 0,02 & 0,02 & 0,03 & 0,02 & 0,03 & 0,01 & 0,07 & 0,01 \\
\hline W12 & 0,10 & 0,08 & 0,11 & 0,07 & 0,05 & 0,11 & 0,05 & 0,03 & 0,09 & 0,02 & 0,13 & 0,06 & 0,07 & 0,15 \\
\hline W13 & 0,02 & 0,03 & 0,11 & 0,07 & 0,15 & 0,02 & 0,05 & 0,10 & 0,03 & 0,11 & 0,03 & 0,06 & 0,07 & 0,05 \\
\hline W14 & 0,10 & 0,14 & 0,11 & 0,07 & 0,05 & 0,08 & 0,05 & 0,03 & 0,09 & 0,02 & 0,13 & 0,02 & 0,07 & 0,05 \\
\hline
\end{tabular}

Tablo 6. Zayıf yönlerin ăgırlıkları

\begin{tabular}{|c|c|c|c|c|c|c|c|c|c|c|c|c|c|}
\hline W1 & W2 & W3 & W4 & W5 & W6 & W7 & W8 & W9 & W10 & W11 & W12 & W13 & W14 \\
\hline 0,03 & 0,03 & 0,11 & 0,08 & 0,14 & 0,02 & 0,05 & 0,12 & 0,04 & 0,13 & 0,03 & 0,08 & 0,06 & 0,07 \\
\hline
\end{tabular}

Yapılan AHP analizinden çıkan sonuca göre 'W5' kriteri en kötü sonuç çıkmıştır. Biyolojik kaçakçılıkla ilgili sorunlar yani biyokaçakçılık ile ilgili sorunlardır.

\subsubsection{Firsatların AHP ile analizi}

Fırsatlara ait alt faktörlerin karşılaştırılmalarının yapıldı̆̆ 1 matris Tablo 7'de normalize edilmiş karşılaştırma matrisi Tablo 8'de ve sonuç ağırlıklar matrisi ise Tablo 9'da verilmiştir. 
Tablo 7. Firsatların karşılaştırma matrisi

\begin{tabular}{|l|l|l|l|l|l|l|l|l|l|l|l|l|l|l|}
\hline & O1 & O2 & O3 & O4 & O5 & O6 & O7 & O8 & O9 & O10 & O11 & O12 & O13 & O14 \\
\hline O1 & 1 & 1 & 3 & 3 & 3 & 1 & 5 & 7 & 5 & 5 & 5 & 5 & 7 & 7 \\
\hline O2 & 1 & 1 & 3 & 3 & 3 & 1 & 5 & 7 & 5 & 5 & 5 & 5 & 7 & 7 \\
\hline $\mathrm{O} 3$ & $1 / 3$ & $1 / 3$ & 1 & 1 & 1 & $1 / 3$ & 5 & 5 & 5 & 5 & 5 & 5 & 5 & 5 \\
\hline $\mathrm{O} 4$ & $1 / 3$ & $1 / 3$ & 1 & 1 & $1 / 3$ & $1 / 5$ & 1 & 3 & 3 & 1 & 3 & 3 & 3 & 3 \\
\hline $\mathrm{O} 5$ & $1 / 3$ & $1 / 3$ & 1 & 3 & 1 & $1 / 5$ & 3 & 3 & 3 & 3 & 5 & 3 & 3 & 3 \\
\hline $\mathrm{O} 6$ & 1 & 1 & 1 & 5 & 5 & 1 & 7 & 7 & 7 & 5 & 7 & 5 & 7 & 5 \\
\hline $\mathrm{O} 7$ & $1 / 5$ & $1 / 5$ & 3 & 1 & $1 / 3$ & $1 / 7$ & 1 & 3 & 3 & $1 / 3$ & 3 & $1 / 3$ & 5 & 1 \\
\hline $\mathrm{O} 8$ & $1 / 7$ & $1 / 7$ & $1 / 5$ & $1 / 3$ & $1 / 3$ & $1 / 7$ & $1 / 3$ & 1 & 1 & $1 / 3$ & 1 & $1 / 3$ & 3 & 1 \\
\hline $\mathrm{O} 9$ & $1 / 5$ & $1 / 5$ & $1 / 5$ & $1 / 3$ & $1 / 3$ & $1 / 7$ & $1 / 3$ & 1 & 1 & $1 / 3$ & 1 & $1 / 3$ & 3 & 1 \\
\hline $\mathrm{O} 10$ & $1 / 5$ & $1 / 5$ & $1 / 5$ & 1 & $1 / 3$ & $1 / 5$ & 3 & 3 & 3 & 1 & 3 & 1 & 3 & 3 \\
\hline $\mathrm{O} 11$ & $1 / 5$ & $1 / 5$ & $1 / 5$ & $1 / 3$ & $1 / 5$ & $1 / 7$ & $1 / 3$ & 1 & 1 & $1 / 3$ & 1 & $1 / 3$ & 1 & 1 \\
\hline $\mathrm{O} 12$ & $1 / 5$ & $1 / 5$ & $1 / 5$ & $1 / 3$ & $1 / 3$ & $1 / 5$ & 3 & 3 & 3 & 1 & 3 & 1 & 3 & 3 \\
\hline $\mathrm{O} 13$ & $1 / 7$ & $1 / 7$ & $1 / 5$ & $1 / 3$ & $1 / 3$ & $1 / 7$ & $1 / 5$ & $1 / 3$ & $1 / 3$ & $1 / 3$ & 1 & $1 / 3$ & 1 & 1 \\
\hline $\mathrm{O} 14$ & $1 / 7$ & $1 / 7$ & $1 / 5$ & $1 / 3$ & $1 / 3$ & $1 / 5$ & 1 & 1 & 1 & $1 / 3$ & 1 & $1 / 3$ & 1 & 1 \\
\hline
\end{tabular}

Tablo 8. Normalize edilmiş firsatlar matrisi

\begin{tabular}{|l|l|l|l|l|l|l|l|l|l|l|l|l|l|l|}
\hline & O1 & O2 & O3 & O4 & O5 & O6 & O7 & O8 & O9 & O10 & O11 & O12 & O13 & O14 \\
\hline O1 & 0,18 & 0,18 & 0,21 & 0,15 & 0,19 & 0,20 & 0,14 & 0,15 & 0,12 & 0,18 & 0,11 & 0,17 & 0,13 & 0,17 \\
\hline O2 & 0,18 & 0,18 & 0,21 & 0,15 & 0,19 & 0,20 & 0,14 & 0,15 & 0,12 & 0,18 & 0,11 & 0,17 & 0,13 & 0,17 \\
\hline O3 & 0,06 & 0,06 & 0,07 & 0,05 & 0,06 & 0,07 & 0,14 & 0,11 & 0,12 & 0,18 & 0,11 & 0,17 & 0,10 & 0,12 \\
\hline O4 & 0,06 & 0,06 & 0,07 & 0,05 & 0,02 & 0,04 & 0,03 & 0,07 & 0,07 & 0,04 & 0,07 & 0,10 & 0,06 & 0,07 \\
\hline O5 & 0,06 & 0,06 & 0,07 & 0,15 & 0,06 & 0,04 & 0,09 & 0,07 & 0,07 & 0,11 & 0,11 & 0,10 & 0,06 & 0,07 \\
\hline O6 & 0,18 & 0,18 & 0,07 & 0,25 & 0,32 & 0,20 & 0,20 & 0,15 & 0,17 & 0,18 & 0,16 & 0,17 & 0,13 & 0,12 \\
\hline O7 & 0,04 & 0,04 & 0,21 & 0,05 & 0,02 & 0,03 & 0,03 & 0,07 & 0,07 & 0,01 & 0,07 & 0,01 & 0,10 & 0,02 \\
\hline O8 & 0,03 & 0,03 & 0,01 & 0,02 & 0,02 & 0,03 & 0,01 & 0,02 & 0,02 & 0,01 & 0,02 & 0,01 & 0,06 & 0,02 \\
\hline O9 & 0,04 & 0,04 & 0,01 & 0,02 & 0,02 & 0,03 & 0,01 & 0,02 & 0,02 & 0,01 & 0,02 & 0,01 & 0,06 & 0,02 \\
\hline O10 & 0,04 & 0,04 & 0,01 & 0,05 & 0,02 & 0,04 & 0,09 & 0,07 & 0,07 & 0,04 & 0,07 & 0,03 & 0,06 & 0,07 \\
\hline O11 & 0,04 & 0,04 & 0,01 & 0,02 & 0,01 & 0,03 & 0,01 & 0,02 & 0,02 & 0,01 & 0,02 & 0,01 & 0,02 & 0,02 \\
\hline O12 & 0,04 & 0,04 & 0,01 & 0,02 & 0,02 & 0,04 & 0,09 & 0,07 & 0,07 & 0,04 & 0,07 & 0,03 & 0,06 & 0,07 \\
\hline O13 & 0,03 & 0,03 & 0,01 & 0,02 & 0,02 & 0,03 & 0,01 & 0,01 & 0,01 & 0,01 & 0,02 & 0,01 & 0,02 & 0,02 \\
\hline O14 & 0,03 & 0,03 & 0,01 & 0,02 & 0,02 & 0,04 & 0,03 & 0,02 & 0,02 & 0,01 & 0,02 & 0,01 & 0,02 & 0,02 \\
\hline
\end{tabular}

Tablo 9. Firsatların ă̆ırlıkları

\begin{tabular}{|l|l|l|l|l|l|l|l|l|l|l|l|l|l|}
\hline O1 & O2 & O3 & O4 & O5 & O6 & O7 & O8 & O9 & O10 & O11 & O12 & O13 & O14 \\
\hline 0,16 & 0,16 & 0,10 & 0,06 & 0,08 & 0,18 & 0,05 & 0,02 & 0,02 & 0,05 & 0,02 & 0,05 & 0,02 & 0,02 \\
\hline
\end{tabular}

Yapılan AHP analizinden çıkan sonuca göre 'O6' kriteri en iyi sonuç çıkmıştır. Nitelikli ve genç insan kaynağının çalışma hayatına katılımı yani nitelikli ve genç insan kaynağının çalışma hayatına katılması.

\subsubsection{Tehditlerin AHP ile analizi}

Tehditlere ait alt faktörlerin karşılaştırılmalarının yapıldığı matris Tablo 10'da normalize edilmiş karşılaştırma matrisi Tablo 11 'de ve sonuç ağırlıklar matrisi ise Tablo 12 'de verilmiştir. 
Tablo 10. Tehditler karşılaştırma matrisi

\begin{tabular}{|l|l|l|l|l|l|l|l|l|l|l|l|l|l|l|}
\hline & $\mathrm{T} 1$ & $\mathrm{~T} 2$ & $\mathrm{~T} 3$ & $\mathrm{~T} 4$ & $\mathrm{~T} 5$ & $\mathrm{~T} 6$ & $\mathrm{~T} 7$ & $\mathrm{~T} 8$ & $\mathrm{~T} 9$ & $\mathrm{~T} 10$ & $\mathrm{~T} 11$ & $\mathrm{~T} 12$ & $\mathrm{~T} 13$ & $\mathrm{~T} 14$ \\
\hline $\mathrm{T} 1$ & 1 & 5 & 3 & $1 / 7$ & 3 & 3 & $1 / 3$ & 3 & 5 & $1 / 3$ & $1 / 3$ & 3 & 1 & $1 / 7$ \\
\hline $\mathrm{T} 2$ & $1 / 5$ & 1 & 3 & $1 / 5$ & 3 & 7 & 3 & 5 & 7 & 3 & 3 & 7 & 5 & $1 / 5$ \\
\hline $\mathrm{T} 3$ & $1 / 3$ & $1 / 3$ & 1 & $1 / 7$ & $1 / 3$ & 3 & $1 / 3$ & 3 & 3 & $1 / 5$ & $1 / 5$ & 1 & 1 & $1 / 7$ \\
\hline $\mathrm{T} 4$ & 7 & 5 & 7 & 1 & 5 & 7 & 3 & 7 & 9 & 5 & 5 & 7 & 5 & 3 \\
\hline $\mathrm{T} 5$ & $1 / 3$ & $1 / 3$ & 3 & $1 / 5$ & 1 & 3 & $1 / 3$ & 5 & 5 & $1 / 3$ & $1 / 5$ & 3 & 3 & $1 / 5$ \\
\hline $\mathrm{T} 6$ & $1 / 3$ & $1 / 7$ & $1 / 3$ & $1 / 7$ & $1 / 3$ & 1 & $1 / 3$ & 1 & 3 & $1 / 3$ & $1 / 5$ & 1 & 1 & $1 / 5$ \\
\hline $\mathrm{T} 7$ & 3 & $1 / 3$ & 3 & $1 / 3$ & 3 & 3 & 1 & 5 & 5 & 1 & $1 / 3$ & 5 & 5 & $1 / 5$ \\
\hline $\mathrm{T} 8$ & $1 / 3$ & $1 / 5$ & $1 / 3$ & $1 / 7$ & $1 / 5$ & 1 & $1 / 5$ & 1 & 3 & $1 / 3$ & $1 / 5$ & 1 & 1 & $1 / 5$ \\
\hline $\mathrm{T} 9$ & $1 / 5$ & $1 / 7$ & $1 / 3$ & $1 / 9$ & $1 / 5$ & $1 / 3$ & $1 / 5$ & $1 / 3$ & 1 & $1 / 5$ & $1 / 7$ & $1 / 3$ & $1 / 3$ & $1 / 9$ \\
\hline $\mathrm{T} 10$ & 3 & $1 / 3$ & 5 & $1 / 5$ & 3 & 3 & 1 & 3 & 5 & 1 & $1 / 3$ & 5 & 5 & $1 / 5$ \\
\hline $\mathrm{T} 11$ & 3 & $1 / 3$ & 5 & $1 / 5$ & 5 & 5 & 3 & 5 & 7 & 3 & 1 & 5 & 5 & $1 / 3$ \\
\hline $\mathrm{T} 12$ & $1 / 3$ & $1 / 7$ & 1 & $1 / 7$ & $1 / 3$ & 1 & $1 / 5$ & 1 & 3 & $1 / 5$ & $1 / 5$ & 1 & 1 & $1 / 7$ \\
\hline $\mathrm{T} 13$ & 1 & $1 / 5$ & 1 & $1 / 5$ & $1 / 3$ & 1 & $1 / 5$ & 1 & 3 & $1 / 5$ & $1 / 5$ & 1 & 1 & $1 / 7$ \\
\hline $\mathrm{T} 14$ & 7 & 5 & 7 & $1 / 3$ & 5 & 5 & 5 & 5 & 9 & 5 & 3 & 7 & 7 & 1 \\
\hline
\end{tabular}

Tablo 11. Normalize edilmiş tehditler matrisi

\begin{tabular}{|l|l|l|l|l|l|l|l|l|l|l|l|l|l|l|}
\hline & T1 & T2 & T3 & T4 & T5 & T6 & T7 & T8 & T9 & T10 & T11 & T12 & T13 & T14 \\
\hline T1 & 0,04 & 0,27 & 0,08 & 0,04 & 0,10 & 0,07 & 0,02 & 0,07 & 0,07 & 0,02 & 0,02 & 0,06 & 0,02 & 0,02 \\
\hline T2 & 0,01 & 0,05 & 0,08 & 0,06 & 0,10 & 0,16 & 0,17 & 0,11 & 0,10 & 0,15 & 0,21 & 0,15 & 0,12 & 0,03 \\
\hline T3 & 0,01 & 0,02 & 0,03 & 0,04 & 0,01 & 0,07 & 0,02 & 0,07 & 0,04 & 0,01 & 0,01 & 0,02 & 0,02 & 0,02 \\
\hline T4 & 0,26 & 0,27 & 0,18 & 0,29 & 0,17 & 0,16 & 0,17 & 0,15 & 0,13 & 0,25 & 0,35 & 0,15 & 0,12 & 0,48 \\
\hline T5 & 0,01 & 0,02 & 0,08 & 0,06 & 0,03 & 0,07 & 0,02 & 0,11 & 0,07 & 0,02 & 0,01 & 0,06 & 0,07 & 0,03 \\
\hline T6 & 0,01 & 0,01 & 0,01 & 0,04 & 0,01 & 0,02 & 0,02 & 0,02 & 0,04 & 0,02 & 0,01 & 0,02 & 0,02 & 0,03 \\
\hline T7 & 0,11 & 0,02 & 0,08 & 0,10 & 0,10 & 0,07 & 0,06 & 0,11 & 0,07 & 0,05 & 0,02 & 0,11 & 0,12 & 0,03 \\
\hline T8 & 0,01 & 0,01 & 0,01 & 0,04 & 0,01 & 0,02 & 0,01 & 0,02 & 0,04 & 0,02 & 0,01 & 0,02 & 0,02 & 0,03 \\
\hline T9 & 0,01 & 0,01 & 0,01 & 0,03 & 0,01 & 0,01 & 0,01 & 0,01 & 0,01 & 0,01 & 0,01 & 0,01 & 0,01 & 0,02 \\
\hline T10 & 0,11 & 0,02 & 0,13 & 0,06 & 0,10 & 0,07 & 0,06 & 0,07 & 0,07 & 0,05 & 0,02 & 0,11 & 0,12 & 0,03 \\
\hline T11 & 0,11 & 0,02 & 0,13 & 0,06 & 0,17 & 0,12 & 0,17 & 0,11 & 0,10 & 0,15 & 0,07 & 0,11 & 0,12 & 0,05 \\
\hline T12 & 0,01 & 0,01 & 0,03 & 0,04 & 0,01 & 0,02 & 0,01 & 0,02 & 0,04 & 0,01 & 0,01 & 0,02 & 0,02 & 0,02 \\
\hline T13 & 0,04 & 0,01 & 0,03 & 0,06 & 0,01 & 0,02 & 0,01 & 0,02 & 0,04 & 0,01 & 0,01 & 0,02 & 0,02 & 0,02 \\
\hline
\end{tabular}

Tablo 12. Tehditlerin ăgırlıkları

\begin{tabular}{|c|c|c|c|c|c|c|c|c|c|c|c|c|c|}
\hline T1 & T2 & T3 & T4 & T5 & T6 & T7 & T8 & T9 & T10 & T11 & T12 & T13 & T14 \\
\hline 0,06 & 0,11 & 0,03 & 0,22 & 0,05 & 0,02 & 0,07 & 0,02 & 0,01 & 0,07 & 0,11 & 0,02 & 0,02 & 0,18 \\
\hline
\end{tabular}

Yapılan AHP analizinden çıkan sonuca göre 'T4' kriteri en kötü sonuç çıkmıştır. İklim değişikliği ve çevre kirliliği yani iklim değişikliği ve çevre kirliliğidir.

\section{Sonuç}

Yapılan AHP analizinden çıkan sonuca göre 'S6' kriteri en iyi sonuç çıkmıştır. Güçlü teknolojik altyapı yani güçlü teknolojik altyapıdır. Buradan çıkan sonuç iki kuruma denk gelmektedir. Bunlar Maliye Bakanlığ Bakanlığıdır. Siber tehditlere karşı teknolojimizi güçlendirmemiz gerektiği, dünyayla beraber hızla gelişen teknolojiye ayak uydurmak için trendleri takip etmeli ve alt yapıların güçlendirilmesi için yazılım alanında teşvikler yapılmalı ve daha fazla bütçe ayrılmalıdır.

Yapılan AHP analizinden çıkan sonuca göre 'W5' kriteri en kötü sonuç çıkmıştır. Biyolojik kaçakçılıkla ilgili sorunlar yani biyo-kaçakçılık ile ilgili sorunlardır. Buradan çıkan sonuç Orman ve Su İşleri Bakanlığı kurumuna denk gelmektedir.
Dünyada oluşan küresel sorunlar bitki, hayvan gibi türlerin neslinin tükenmesine ve yok olmasına sebep olmaktadır. Bunun için gen bankaları sayısının arttırılması gerekmektedir. Günümüzde genetik mühendisliği ve biyo-teknolojilerin geliştirilmesi, genlerin, canlı türlerin sürdürülebilirliği ve çeşitliliğini sağlama konusunda önemli mekanizmalar olarak yaygınlaşmaktadır.

Yapılan AHP analizinden çıkan sonuca göre 'O6' kriteri en iyi sonuç çıkmıştır. Nitelikli ve genç insan kaynağının çalışma hayatına katılımı yani nitelikli ve genç insan kaynağının çalışma hayatına katılması. Buradan çıkan sonuç Çalışma ve Sosyal Güvenlik Bakanlığı denk gelmektedir. Öneri olarak; genç ve nitelikli popülasyonu desteklemek adına insan gücünü artırmak için gerekli tedbirlerin araştırılması ve uygulanması, gençleri teşvik edip hayat seviyelerinin yükseltilmesinin amaçlanması, sosyal güvenlik imkânının yaygınlaştırılması gibi iyileştirmeler yapabilir.

Yapılan AHP analizinden çıkan sonuca göre 'T4' kriteri en kötü sonuç çıkmıştır. İklim değişikliği ve çevre kirliliği yani 443 
iklim değişikliği ve çevre kirliliğidir. Buradan çıkan sonuç Gıda Tarım ve Hayvancılık Bakanlığına denk gelmektedir. İklim değişikliği sonucu dünyada yaşayan canlılara tehdit oluşturduğu için kaynak kullanımlarının daha düzenli şekilde kullanılması, su israfının önüne geçilmesi, hava kirliliği için gereken önlemlerin alınması adına çalışma yapılması ve insanların bu konular hakkında bilinçlendirilmesi gereklidir.

Bu çalışma Tübitak 2209-A kapsamında desteklenmiştir.

\section{Kaynakça}

Abdel-Basset, M., Mohamed. M., \& Smarandache, F. (2018). An Extension of Neutrosophic AHP-SWOT Analysis for Strategic Planning and Decision-Making. Symmetry 10, 116; doi:10.3390/sym10040116.

Büyüközkan, G.,Mukul, E., Kongar, E., Socio-Economic Planning Sciences, https://doi.org/10.1016/j.seps.2020.10092

Deutsch, G. (2010).RapidMiner from Rapid-I at CeBIT. Data Mining Blog, March 18.

Güryeli M. (2016). Ar-Ge projeleri seçim probleminin AHP yöntemi ile incelenmesi: Kamu destekli teknolojik ürün yatırım destek programı üzerine bir uygulama Adnan Menderesi Üniversitesi, Sosyal Bilimler Enstitüsü, İşletme Anabilim Dalı, Yüksek Lisans Tezi.

He W., Zha S. \& Li L. (2013). Social media competitive analysis and text mining: A case study in the pizza industry. International Journal of Information Management 33, 464472.

Karaman A. E. (2011). Üniversitelerin stratejik planlarındaki swot analizleri, İnönü Üniversitesi Eğitim Bilimleri Enstitüsü Eğitim Bilimleri Anabilim Dalı / Eğitim Yönetimi ve Denetimi Bilim Dalı.

Kumar, A., Dabas, V., \& Hood, P. (2020). Text classification algorithms for mining unstructured data: a SWOT analysis,
International Journal of Information Technology volume 12, pages1159-1169.

Norris, D. (2013). RapidMiner - a potential game changer. ITDirector.com, November 22.

Okumuş B. (2007). Kamu kuruluşları stratejik planlama sürecinde paylaşılan vizyon oluşturulması: İstanbul Büyükşehir Belediyesi Örneği, Marmara Üniversitesi, Sosyal Bilimler Enstitüsü, Yüksek Lisans Tezi

Palka, G., Oliveira, E., Pagliarin, S., \& Hersperger, A. M. Strategic spatial planning and efficacy: an analytic hierarchy process (AHP) approach in Lyon and Copenhagen, European Planning Studies https://doi.org/10.1080/09654313.2020.1828291

Rojas, C. V., Reyes, E. R., Hernández, F. A. \& Robles, G. C. (2018). Integration of a text mining approach in the strategic planning process of small and medium-sized enterprises, Industrial Management \& Data Systems Vol. 118 No. 4, 745-764.

Saaty, T.L. (1988). What is the analytic hierarchy process? In Mathematical Models for Decision Supported; Springer: Berlin, Germany, pp. 109-121

Şeker, Ş. E., (2012). Turkish Query Engine on Library Ontology. IKE12, Internet Knowledge Engineering, ISBN:1-60132222-4, Pages:26-33

Turban E., Sharda R., \& Delen D. (2011). Decision Support and Business Intelligence Systems (9. Bask1). Upper Saddle River, New Jersey: Prentice Hall.

Vaidya, O.S., Kumar, S. (2006). Analytic hierarchy process: An overview of applications. European Journal of Operational Research, 2006, 169, 1-29.

Yunus, E. (2019). Stratejik yönetimde Swot analizi ve bir işletmede uygulanması, İstanbul Kültür Üniversitesi, Sosyal Bilimler Ensititüsü, İșletme Anabilim Dalı, Yüksek Lisans Tezi. 